\title{
How do we know when the change is optimal?
}

\author{
Lazăr Latu, Neamt Prefecture, Romania \\ Roxana Latu , „Al. I. Cuza” University Iasi, Romania
}

\begin{abstract}
The analysis of the external environment must not be limited to the identification of the external factors, but must also take into account their importance. The real management capacity consists of finding out their signification, of identifying exactly those factors which may have a special influence upon the organization. As a consequence of the fact that the external environment is dynamic, it is important to understand correctly the direction of the moment and the location of the change.
\end{abstract}

\section{Keywords}

Change, sigmoid curve, paradox, attitude

\section{JEL Codes: 012}

\section{Factors requiring the change}

Nowadays, the change represents the core of the management experience and practice. Any organization exists and functions within an environment which has an influence on the shape, determines its structure, offers it opportunities and threatens it. Among these factors, the most important are the clients and the competence; without effectively knowing it, it is not likely for an organization to survive, or to thrive.

With all their importance, clients and competence do not form the entire external environment, as there are many other factors, beyond the organization's control, which may have significant effects on its performances and perspectives.

The analysis of the external environment must not be limited to the identification of the external factors, but must also take into account their importance. The real management capacity consists of finding out their signification, of identifying exactly those factors which may have a special influence upon the organization. As a consequence of the fact that the external environment is dynamic, it is important to understand correctly the direction of the moment and the location of the change.

Accepting the change, working in an environment which is in a continuous change, analysing the change and actively getting into this change had ceased to be occasional management features, becoming fundamental requirements of the function.

Paradoxically, but true, the person upon whom you have maximum control is yourself, and the person whom you change very hard is also yourself. The transformation may start only when something ends and something new takes its place. For this thing to happen we must give up the old, even if we do not have any guarantee for what the new will bring.

The solution for the transformation of the negative aspects of this change into positive ones, is the capacity of the manager to foresee the resistance and to analyse the reasons for which people and teams oppose to this change.

So far we have defined the external factors imposing the change and we have assessed the internal organizational capacity. But even you yourself are one of the most important 
connections for this change. Your attitudes, your enthusiasm, your willingness to allow your employees' reactions influence the change while this becomes reality, your availability to change yourself.

Whether we have to deal with a re-organization, an acquisition, a re-technology or a removal of the company, the key factor of a successful transformation will be ourselves and our attitude.

To the question whether the change is a good or a bad thing, the answer should be "depends on...". Depends on the reasons of this change, on the fact that the benefits of this change do or do not exceed the costs. So, which are the reasons for which some people talk about a change with enthusiasm, while others see it as a threat. These attitudes seem to depend on the position one has; if you are the one initiating the change or if you are at the other end, of those standing for its consequences.

Whether we like it or not, the change is part of our life. The organizations are never static, they always suffer one change or another. The common feature is when something changesaccidentally or as a consequence of a plan or of some decisions of the members of an organization-the change always has consequences which may be positively accepted, rejected or ignored by different persons within the organization, and their reactions do have other implications.

\section{Sigmoid curve- the way through paradoxes}

If you think you know the way to the future since it is only a continuation of the one reached so far, you might as well get to another place. The sigmoid curve (fig. nr. 1) is an S-type curve, which has been a problem since ancient times.

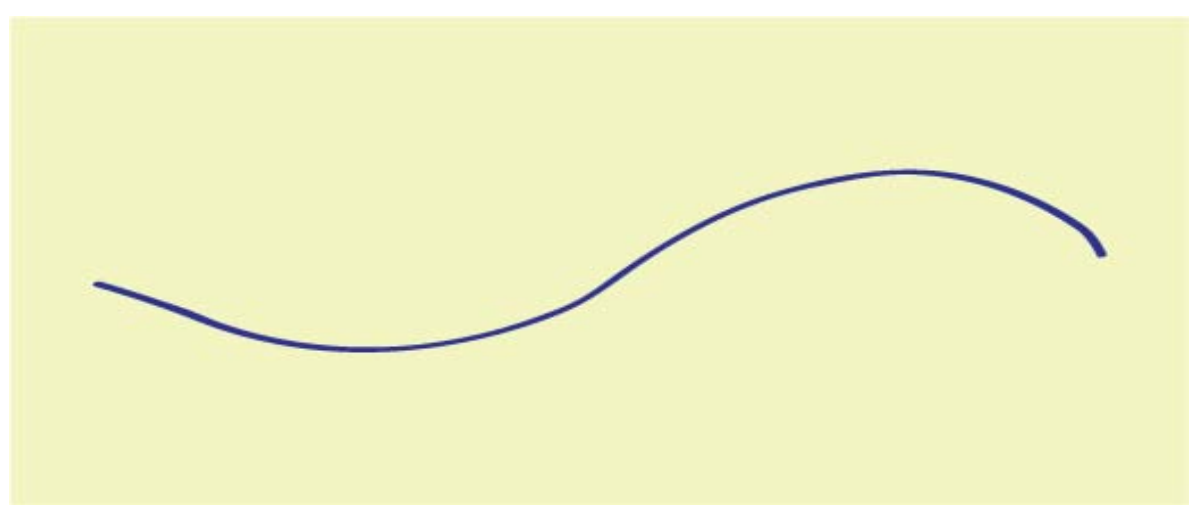

Fig nr. 1 The sigmoid curve; Source: Handy C. -The Empty Raincoalt, Codecs, Bucharest, 2007

The sigmoid curve is the story of life itself. We go on life easily, experimenting, making errors, we grow up as we grow up, and then we start from the beginning. It represents the life cycle of each product, of the cycle it grows up in, and where many organizations go down, describing even the evolution of love and relationships.

Fortunately, life is more than this curve (if life would mean only this, it would be kind of depressing, since every discussion about it would only be the exact place we sit at that moment on the curve, and what measuring unit the time axle has)

The secret for a continuous development is to launch on a new sigmoid curve before the first one ends. The best starting point for a new curve is point $\mathbf{A}$ (fig. nr. 2), where there is still 
enough time and enough resources and energy to go to a new curve in the initial phase of exploration and failures, before the first curve starts from the beginning.

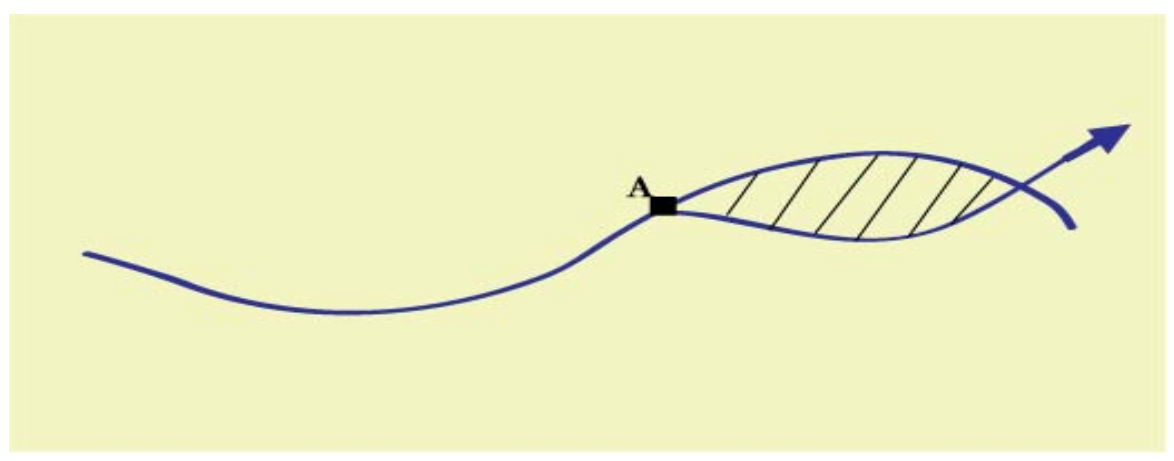

Fig. nr. 2. Point A of sigmoid curve. Source.. Handy C. -The Empty Raincoalt, Codecs., Bucharest, 2007

For an obvious thing-this has to be done, just that, at point A, all the messages an individual or an organization receive tell them "everything goes on perfectly" and it would be a stupid thing to change anything, as long as the current prescription has so good results. But what we do know about the change, whether it is personal or organizational, tells us that that the real dynamism for the change starts taking place only when reaching point $\mathbf{B}$ (fig. nr. 3) a curve and we look at the disaster.

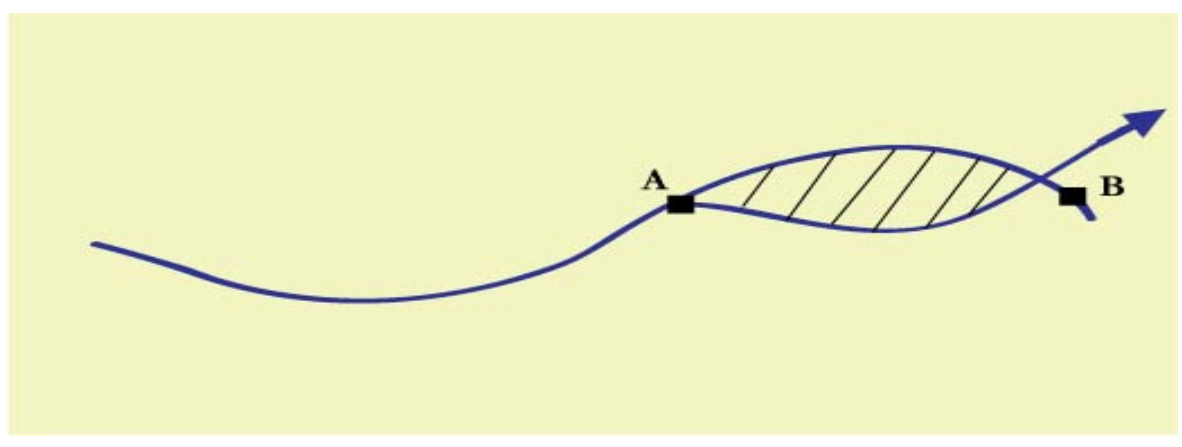

Fig. nr. 3. Point B of sigmoid curve. Source Handy C. - The Empty Raincoalt, Codecs Ed., Bucharest, 2007

But once this point is reached, we need a great effort to extract from that situation and reach the top, where you should be on the second curve. When things go wrong, the leaders of the organization reach to that point being compromised, since they took it down, where the resources and energies decreased.

For the individual, an event such as the reserve, usually takes place when this is on point $\mathbf{B}$. It is difficult for it, at that point, to mobilize the resources or to remake the credibility had on top of the curve. Therefore, we must not be surprised either that people get to be depressed at this point or that any organization postponing launching of the change process till point $\mathbf{B}$ brings new people at the management. Only people coming from outside, have, in this case, the credibility and the fresh vision they need for leading the organization back to the top of the second curve. 
Wise are those who start to the second curve from the very point $\mathbf{A}$, as from there begins the Way through paradox, the way towards building a new future, without giving up the present. But even so, the problem does not end here. The second curve, either it is for a product, a new method of operation, a new strategy or a new culture, will certainly be very different from the old one. And that's the way it should be.

And people themselves must be different. Those drawing the second curve must not be the same to those drawing the first curve. First of all, because the initial leaders must continue having the responsibility for the maintenance of the first curve for a proper time, in order to sustain the first difficult stages of the second curve.

Second of all, these people would find difficult, in their hearts, to give up an action class while it seems to go that well, even if, theoretically speaking, they admit they need a new curve. Therefore, for a while, within an organization, there must coexist new ideas and new people with old ideas and old people, until the second curve is already settled and the first one starts growing dim.

The marked area under the maximum of the first curve therefore represents a period of great confusions. There are two or many groups of people and 2 sets of ideas in mutual competition for the future.

No matter how wise and well-wisher they are, the leaders of the first curve are restless regarding their future when the curve starts going down. They need a great ability to foresee in order to sustain the others and at the same time to plan their own leaving or their own end. Those who can yet do that, finally manage to ensure the rebirth and the continuous growth of their organization. We cannot say it is easy, not even for those extremely cautious, if we read the story below.

The president of a great company talked to his "employees/knights": "I have two messages for you today. First of all, I would like to remind you that we have a big company, very successful, having maybe the greatest success it has ever had. Second of all, if we want to continue gaining success, we must radically change this way of working".

He continued explaining people why he considers that the different future he expects will require different answers, but nobody was listening to him anymore. In their opinion, if there was such a success, it was a stupid thing to change anything.

But the president was right, they were at point $\mathbf{A}$ back then, and looked over the hill, but he did not manage to convince them and implement the required changes.

Three years later, already at point $\mathbf{B}$, the company understood they need to change, but the first person who was attacked and fired was the president himself. He had lost his credibility, and not even the fact that he had been right from the very beginning made him loved among his colleagues.

What is valid for the organization is also valid for the individual and his relationships. A good life is probably a sequence of "the second curve", each of them started before the first one going down for good.

Life and priorities change while the individual grows up and becomes old. Every relationship needs the second curve sometimes. If within a couple's relationship, it is the same story. When they realize they need the second curve, they are already at point $\mathbf{B}$. It is too late to do something together, and so, each partner finds a new partner. That is why it is better to say, as a joke, that you are at the second marriage, but with the same partner, because it is cheaper, because we managed to discover the second curve, very different, and applied it together. We cannot say that the drawn period was not difficult, because we fought to keep the old in our past, and, at the same time, experiment new things.

\section{The discipline of the second curve}

The concept of the sigmoid curve helped many people and organizations understand the confusions they are in, at the moment. And still, the question we must all ask ourselves is: 
„How can we know where we are on the first curve?” A way of answering this question is by making a personal assessment, of the position within the organization, draw the curve as we see it and mark an $\mathbf{X}$ on the place we are right now.

Once the perception about their own curve is discovered, people agree they are way too far along it than they would have admitted previously. They are all much closer to point $\mathbf{B}$ than to point $\mathbf{A}$.

We will certainly know where we are on the curve only when looking back, as it is much easier to see where the others are, than where we are. We must guess, there is no science for such things.

The discipline of the second curve requires us to always suppose that we are around the top of the first one, at point $\mathbf{A}$, and therefore, we must start to prepare for the second curve. The organizations must start from the idea that their current strategies must be replaced within no more than 2 or 3 years and that the life cycle of their products is much shorter than before.

The discipline of the second curve will have its favourable effect, will force people question about their own ideas, about those standing at the base of the first curve, and ask themselves some real questions. It keeps us sceptical, inquisitive, inventive-fundamental attitudes during the period of change-and it is the best way of facing the contradictions accompanying these times.

The discipline of the second curve follows the traditional cycle in 4 stages of the discovery. The process starts with questions. Then the questions lead to ideas, possibilities and assumptions. The best of them are then tested theoretically and in practice. The results of these experiments are reviewed. The first two phases are made up only of time and imagination. The discipline requires us not to recreate the same life, as we would only continue the first curve. The second is always different, though it is based on the first one, and grows up of it.

In order to go on, we need the so called " curvilinear logics", according to which the entire world and all the things in it are really represented by sigmoid curves, and so every thing has pros and cons, ups and downs, and nothing lasts forever.

Example: The production principle Just -In -Time (deliver the goods just in time), has its origin in Japan, being then copied all over the world. The idea of a permanent flow of delivery to the factory, when and if you need it, it is so obvious, if you think about it. You do not need warehouses and storage costs. Unfortunately, the idea has become too popular. We found out that now the traffic around Tokio is almost all the time crowded because of the trucks, and this makes the goods get to the destination "just too late" instead of "just in time".

The costs for being stuck in traffic are way over the old storage costs, not to mention the negative effect of the exhaust gases on the environment. Nothing that is "too much" is good, even if we are talking in theory. The curvilinear logic strikes without mercy. In a world in continuous change, there is no perfect answer, we must be in a continuous search.

\section{References}

1. Burdus, E., şi colab.( 2003), Managementul schimbării, Ed. Economică, Bucureşti

2. Clarke, L. (2002), Managementul schimbării, Ed. Teora, Bucureşti

3. Handy, C. (2007), Pelerina Goală, Ed. Codecs, Bucureşti

4. Hay, J. (2006), Codecs Ed., Bucureşti,

5. Latu, L., Botez, D.( 2008), Provocarea sau necesitatea de a ne schimba, Bucureşti.

6. Rusu, C. (2003), Mangementul schimbării, Ed. Economică, Bucureşti 